\title{
Some factors influencing the release of vitamin A from the liver
}

\author{
By W. A. McGILLIVRAY* \\ Biochemistry Department, Massey Agricultural College (University of New Zealand), \\ Palmerston North, New Zealand
}

(Received 29 August 1960-Revised 22 February 1961)

The release of vitamin A from the liver under either normal or abnormal conditions has been investigated by a number of workers. As Moore (1957) points out in a recent review, it is apparent that a delicate mechanism controls the release of vitamin A so that blood levels normally remain constant in spite of large variations in liver stores. However, despite some contradictory results, it does appear that some treatments may have a marked, if short-term, effect on the rate of release of vitamin A and consequently on blood levels of the vitamin. Thus treatments such as nervous stimulation (Chevallier, Malméjac \& Choron, 1935; Young \& Wald, I940-1) or liver operation (Drummond \& McWalter, 1935; Young \& Wald, 1940-I) result in release of vitamin A from the liver and a corresponding increase in the blood levels. Various hormones also exert a similar influence. Young \& Wald (1940-1), Bauereisen (1939) and Thiele \& Guzinski (1940) report increased blood levels of vitamin A after injections of adrenaline, although Goodwin \& Wilson (1949) and McGillivray, Thompson $\&$ Worker (1958) were unable to confirm these findings. Hormones of the adrenal cortex such as cortisone have also been found to result in rapid depletion of vitamin A reserves (Clark \& Colburn, 1955). A number of other factors are also reviewed by Moore (1957).

The release of vitamin A under normal conditions is much slower than under the influence of such abnormal treatments. It seems reasonable to assume a relatively constant tissue requirement for vitamin $A$ and that it is supplied through a release of vitamin A alcohol into the blood from the liver. However, the rate of loss from the liver is related to the magnitude of liver reserves and an animal does not appear always to use its vitamin A reserves, particularly when they are high, to the best advantage (Moore, I957); the vitamin may be destroyed in the Kupffer cells (Popper \& Brenner, 1942) or released into the body for destruction elsewhere. In the latter connexion the persistence of high levels of vitamin A ester in the blood, long after dosing with vitamin A had ceased, of a patient suffering from hypervitaminosis $\mathrm{A}$ (Gerber, Raab \& Sobel, 1954) is most interesting.

As the result of an error in the compounding of the commercial vitamin A-deficient diet used in this laboratory (McGillivray, Thompson \& Worker, 1956) a large number of young adult rats that would normally have been partially deficient in vitamin A were found to have relatively uniform liver reserves of the order of

\footnotetext{
* Present address: The Dairy Research Institute (N.Z.), Palmerston North, New Zealand. 
130-200 $\mu \mathrm{g}$ vitamin $\mathrm{A} / \mathrm{rat}$. These animals, together with some stock-colony rats with higher and more variable reserves, were therefore used in a series of experiments to study some of the factors influencing the release of vitamin A from the liver.

\section{EXPERIMENTAL AND RESULTS}

Rats. The rats used were albinos of the Wistar strain.

Hormone preparations. Adrenaline solution ( $\mathrm{I}: 1000)$ was supplied by Kempthorne \& Prosser (N.Z.) Ltd; adrenocorticotrophin (ACTH) was a long-acting form (Cortrophin ' $Z$ ', 40 i.u./ml, supplied by Organon Laboratories Ltd); deoxycorticosterone acetate (Organon Laboratories Ltd) was injected as a solution in arachis oil; cortisone acetate (Cortelan, $25 \mathrm{mg} / \mathrm{ml}$ ) was supplied by Glaxo Laboratories (N.Z.) Ltd. The microcrystalline form used in some experiments was prepared by suspending cortisone acetate in normal saline containing $0.2 \%$ carboxymethylcellulose and $0.04 \%$ Tween 80 (polyoxyethylene sorbitan monooleate, Atlas Powder Co., Wilmington, Delaware), as described by Flux (1954).

Assays. Vitamin A was estimated in blood and liver samples by the method of Thompson, Ganguly \& Kon (1949). Preliminary experiments were carried out to determine the accuracy of this method when applied to the small volumes of blood plasma available from individual rats. It appeared that little reliance could be placed on readings equivalent to less than about $5 \mu \mathrm{g}$ vitamin $\mathrm{A} / 100 \mathrm{ml}$ plasma, but that above this threshold level differences of about $2 \mu \mathrm{g} / \mathrm{I} 00 \mathrm{ml}$ plasma were significant.

Effect of liver operation. Under diethyl ether and nembutal (Abbot Laboratories Ltd) anaesthesia a portion of the median lobe was removed from the livers of a number of stock-colony rats. Blood samples were taken from these rats at slaughter $\left(0.5^{-24} \mathrm{~h}\right.$ later $)$ and the remainder of the liver was also removed. Vitamin A levels found in the blood and in the two liver portions in a number of such experiments are shown in Table $\mathrm{r}$. It is apparent that liver operation was generally associated with the release of some vitamin A from the liver and a resultant increase in blood levels. These increases in blood vitamin A alcohol levels were associated with increases in the proportion of vitamin A alcohol in the liver.

A number of rats were subjected to sham operations in which an incision was made, the liver tissue being disturbed but not damaged in any way. Other animals were anaesthetized only. In none of them was the blood vitamin A level found to be significantly different from that of untreated controls.

Effect of adrenaline injections. The adrenaline solution ( $\mathrm{I}: \mathrm{I000})$ was injected intraperitoneally into rats that were then killed at various times after injection. Blood samples were taken from these rats at slaughter, and from untreated control rats, and were assayed individually for vitamin A. From typical results presented in Table 2, it would seem that individual rats vary considerably in their response to adrenaline but that on a number of occasions rats were slaughtered at a time when blood vitamin A levels were higher than normal. In no instances were blood levels of vitamin A ester significantly higher than in normal untreated controls.

Effect of injections of ACTH, cortisone and deoxycorticosterone. The effect of sub- 
cutaneous injections of these hormones on the release of vitamin A from the liver is shown in Tables 3 and 4 . From Table 3 (Expts 1,2 and 5 ) it would appear that the higher concentrations of cortisone caused relatively rapid release of vitamin A from liver stores and elevated blood levels of vitamin A alcohol. There is also an indication

Table I. Effect on the release of vitamin $A$ from the liver of rats of removal of a portion of the median lobe

(Values for individual rats)

Expt no.

Five untreated control rats

Eight anaesthetized or shamoperated rats

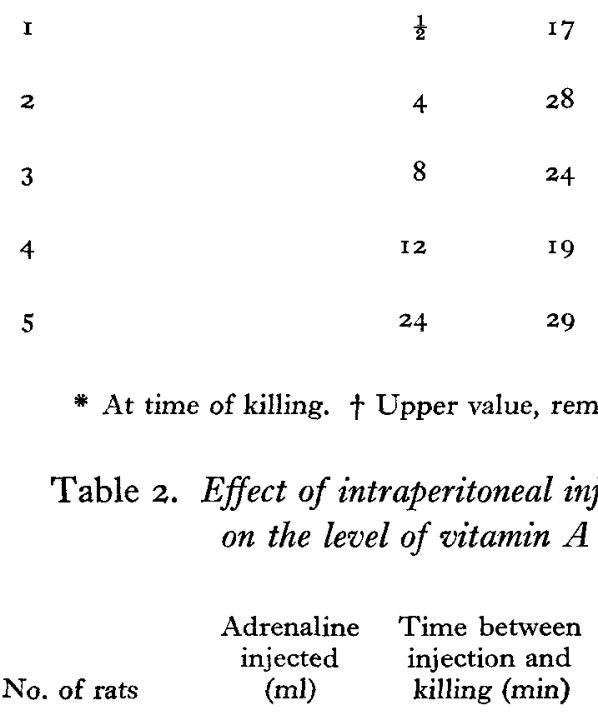

$\begin{array}{rl}\text { I5 } & - \\ 3 & 0.125 \\ 5 & 0.5 \\ 5 & 0.5 \\ 5 & 0.5 \\ 5 & 0.5 \\ 3 & 0.5 \\ 9 & 2.0 \\ 3 & 2.0 \\ 4 & 2.0\end{array}$

Vitamin $A$ in removed lobe and remainder of livert

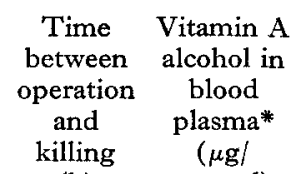

(h)

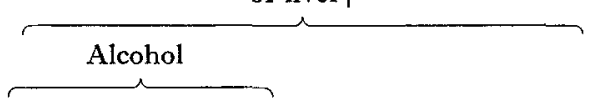

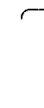

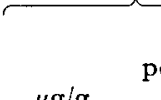

\begin{tabular}{|c|c|c|c|c|c|}
\hline - & $16-18$ & $10-19$ & $4 \cdot 8-11$ & $98-210$ & $I 10-220$ \\
\hline 一 & $16-19$ & $8 \cdot 0-29$ & $6 \cdot 2-15$ & $70-270$ & $82-300$ \\
\hline \multirow[t]{2}{*}{$\frac{1}{2}$} & I7 & 16 & $9 \cdot 5$ & 152 & I 68 \\
\hline & & 14 & $9^{\cdot I}$ & 140 & I 54 \\
\hline \multirow[t]{2}{*}{4} & 28 & 6.8 & $8 \cdot 5$ & 73 & 80 \\
\hline & & 14 & 26 & 46 & 60 \\
\hline \multirow[t]{2}{*}{8} & 24 & 23 & I I & I 86 & 209 \\
\hline & & 30 & I 8 & 142 & 172 \\
\hline \multirow[t]{2}{*}{12} & I9 & $4 \cdot I$ & $4 \cdot 9$ & 79 & $8_{3}$ \\
\hline & & 3.0 & $4 \cdot 5$ & 63 & 66 \\
\hline \multirow[t]{2}{*}{24} & 29 & 22 & $8 \cdot 2$ & 248 & 270 \\
\hline & & 18 & 12 & 132 & 150 \\
\hline
\end{tabular}
(n) 


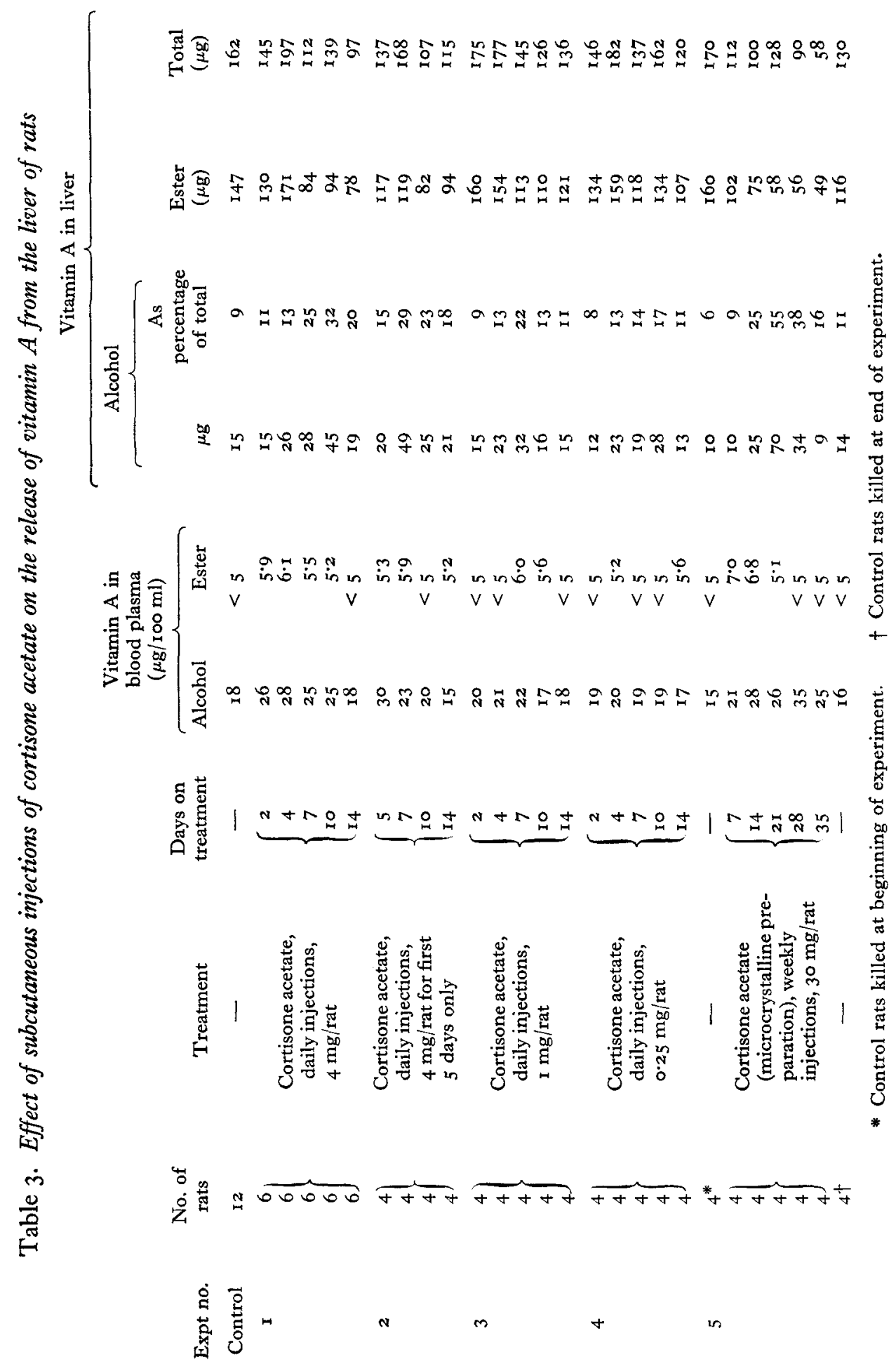


Vol. I5

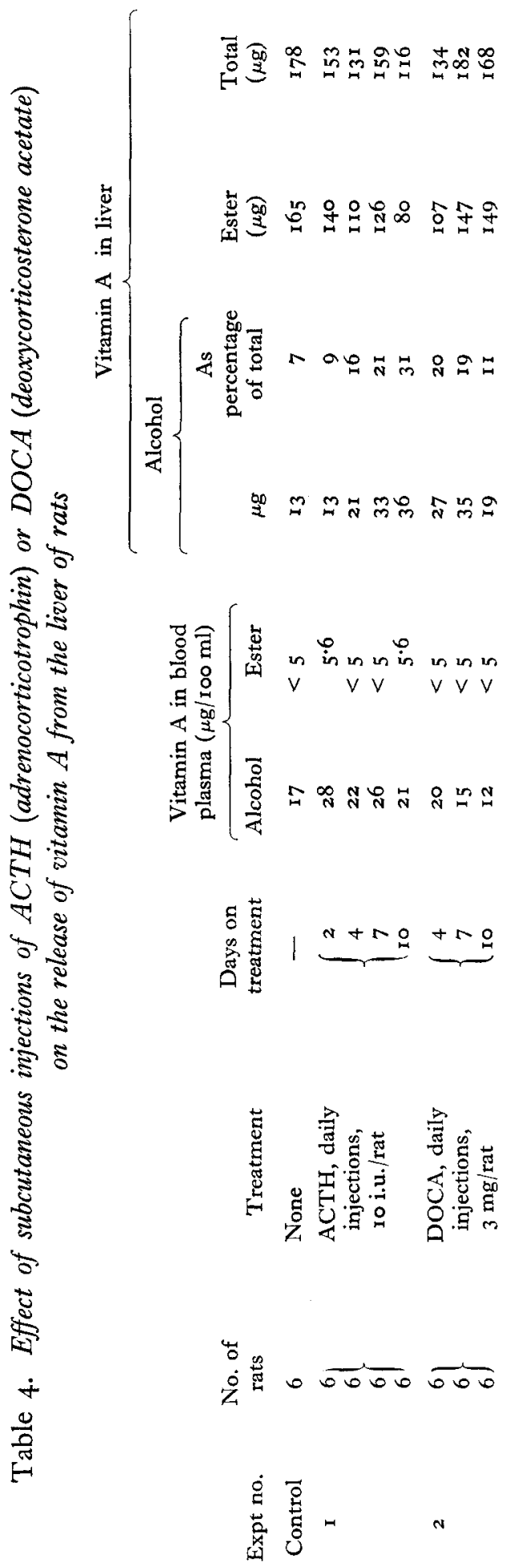


vitamin A alcohol. The effect of cortisone was apparent for some time after injections ceased (Expt 2).

From Table 4 it would seem that injections of ACTH also caused an increased release of vitamin A from the liver and elevated blood levels of vitamin A alcohol. No such effect was apparent with deoxycorticosterone, blood levels of vitamin A alcohol tending to decrease slightly with treatment. This was probably a dilution effect associated with the general oedema produced by this hormone.

Table 5. Levels of vitamin $A$ in the blood and liver of rats during a period of massive dosing with vitamin $A$ and a subsequent period on a vitamin $A$-deficient diet

\begin{tabular}{|c|c|c|c|c|c|c|c|c|}
\hline \multirow{4}{*}{$\begin{array}{l}\text { No. } \\
\text { of rats }\end{array}$} & \multirow{4}{*}{$\begin{array}{l}\text { Duration } \\
\text { of } \\
\text { experiment } \\
\text { (weeks) }\end{array}$} & \multirow{4}{*}{$\begin{array}{l}\text { Time on } \\
\text { deficient } \\
\text { diet } \\
\text { (weeks) }\end{array}$} & & & \multicolumn{4}{|c|}{ Vitamin $\mathrm{A}$ in liver } \\
\hline & & & & & \multicolumn{2}{|c|}{ Alcohol } & \multirow{3}{*}{$\begin{array}{l}\text { Ester } \\
(\mu g)\end{array}$} & \multirow{3}{*}{$\begin{array}{l}\text { Total } \\
(\mu \mathrm{g})\end{array}$} \\
\hline & & & \multicolumn{2}{|c|}{$\begin{array}{l}\text { Vitamin } \mathrm{A} \text { in blood } \\
\text { plasma }(\mu \mathrm{g} / \mathrm{s} 00 \mathrm{ml})\end{array}$} & & $\begin{array}{l}\text { As } \\
\text { percen- } \\
\text { tage }\end{array}$ & & \\
\hline & & & Alcohol & Ester & $\mu \mathrm{g}$ & total & & \\
\hline 4 & $\circ$ & - & I5 & $<5$ & 18 & I I & 152 & 170 \\
\hline 2 & 2 & - & 25 & 66 & 1320 & 5 & 24600 & 25900 \\
\hline 2 & 4 & - & 40 & 165 & 2460 & 7 & 32000 & 34500 \\
\hline 4 & 5 & $\mathbf{I}$ & 29 & 33 & 1380 & 4 & 36500 & 37900 \\
\hline 4 & 6 & 2 & I7 & 25 & 1240 & 5 & 24200 & 25400 \\
\hline 4 & 7 & 3 & 18 & 20 & 1020 & 3 & 31200 & 32200 \\
\hline 3 & 8 & 4 & 16 & IO & 690 & 3 & 26500 & 27200 \\
\hline 3 & 9 & 5 & I6 & IO & 420 & 3 & 16000 & 16400 \\
\hline 3 & 10 & 6 & I8 & $8 \cdot 3$ & 600 & 5 & 12500 & 13100 \\
\hline
\end{tabular}

The livers of animals treated with cortisone, ACTH or deoxycorticosterone showed marked increases in the proportion of vitamin A present as the alcohol. There was, however, with the adrenocortical hormones, some indication that the animals became conditioned to the treatment, the proportion of vitamin A alcohol in the liver tending to decrease towards a more normal alcohol to ester ratio. With cortisone this decrease was associated with decreases in blood levels of vitamin A alcohol.

In a number of instances blood level of vitamin A ester was slightly above the accepted threshold. The small increases were, however, not statistically significant.

Release of vitamin A from abnormally high liver reserves. Massive reserves of vita$\min \mathrm{A}$ were developed in the livers of a group of rats by giving them free access for a period of 4 weeks to commercial pellets that had been soaked in a proprietary emulsion of vitamin A. The intake of vitamin A was not measured, but would have been up to about 50000 i.u./rat daily. The rats were then placed on the usual vitamin Adeficient diet (McGillivray et al. 1956 ) and were killed at weekly intervals. Table 5 shows the mean levels of vitamin A found in the liver and blood of these rats.

As would be expected, liver reserves were found to be variable, but the rapid accumulation of vitamin $A$ and its subsequent loss when the animals were on the deficient diet is clearly apparent. The proportion of vitamin A in the alcohol form in the liver decreased as total vitamin A storage increased and did not alter appreciably during the period of vitamin A depletion. 
Within I $_{4}$ days after the animals had been placed on the deficient diet, blood levels of vitamin A alcohol had returned to normal, but the animals, although no longer absorbing vitamin A, had blood ester levels higher than normal for at least 6 weeks.

\section{DISCUSSION}

From the results presented here, it seems clear that the rate of depletion of liver stores of vitamin A and the levels of vitamin A alcohol in the blood can be markedly influenced by treatment with various hormones. The effect seems clearly established with ACTH and cortisone, confirming the earlier findings of Clark \& Colburn (1955) and Wang, Glass, Goldenberg, Stearns, Kelly \& Jackson (1954), but is more equivocal with adrenaline. Of the forty-two treated animals (Table 2) only fourteen showed elevated blood levels of vitamin A at time of slaughter. It would therefore appear that rats vary considerably in their response to adrenaline, either in the magnitude of the change in blood levels of vitamin $\mathrm{A}$ or in the time after injection at which the apparently transitory increase occurs. This variation may explain earlier conflicting findings about the effect of adrenaline on the level of vitamin A in the blood (cf. Young \& Wald, 1940-I; Bauereisen, 1939; Thiele \& Guzinski, I940; Goodwin \& Wilson, 1949; McGillivray et al. 1958). The loss of vitamin A from the liver after liver operation confirms the findings of Drummond \& McWalter (I935) and Young $\&$ Wald (1940-I), although the increases found in blood vitamin $A$ in the rats were much smaller than reported for rabbits by the latter workers. This, and other differences in rates of depletion between the results reported here and those obtained by other workers, could be explained by species differences and by differences in the age and vitamin status of the animals and the dosing procedures.

The multiplicity of effects associated with the hormones injected or with those released through the surgical shock associated with liver operation precludes us from advancing, at this stage of knowledge of hormone action, any reasonable theory to explain the increased rate of loss of vitamin A from the liver and the elevated blood levels of vitamin A alcohol. It was, however, always the alcohol form of vitamin A that increased and except with adrenaline, when the effect was too small and transitory to alter liver storage measurably, the proportion of vitamin $\mathrm{A}$ in the alcohol form increased in the liver. It is a matter of speculation, therefore, whether the effect of the hormones is to alter, in favour of the former, the ratio of vitamin A alcohol to ester in the liver, the alcohol then being merely flushed away by the blood for wasteful destruction elsewhere in the body, or whether the effect is to increase the overall demand of the body for vitamin $\mathrm{A}$, it being met by a more rapid hydrolysis of stored ester and release of the vitamin A alcohol into the blood.

A different situation exists during the loss of rapidly acquired massive reserves of vitamin A. Here, in support of the findings of Gerber et al. (1954), there is evidence of loss of the vitamin in the esterified form into the blood. Persistence of vitamin A ester in the blood for up to 3 weeks after a single massive dose of vitamin A has already been noted with lactating cows (McGillivray, 1957). These findings further indicate the different mode of storage of excessively large quantities of vitamin $A$ in the liver (cf. Popper \& Brenner, 1942). 


\section{SUMMARY}

I. Observations by previous workers that liver operation or subcutaneous injections of adrenocorticotrophin or cortisone results in elevated blood vitamin A levels and more rapid than normal depletion of liver vitamin $A$ reserves have been confirmed with rats. Intraperitoneal injections of adrenaline also sometimes increased blood vitamin $\mathrm{A}$ levels.

2. The increase in blood vitamin $A$ has been shown to occur in the alcohol form and to be associated with an increased proportion of vitamin A alcohol in the liver.

3. In contrast, the rapid loss of abnormally high liver stores of vitamin $A$ is associated with increased levels of vitamin A ester in the blood, the alcohol form remaining normal in amount.

\section{REFERENCES}

Bauereisen, E. (1939). Endokrinologie, 21, 247.

Chevallier, A., Malméjac, J. \& Choron, Y. (1935), C.R. Soc. Biol., Paris, rr9, 739.

Clark, I. \& Colburn, R. W. (1955). Endocrinology, 56, 232.

Drummond, J. C. \& McWalter, R. J. (1935). F. Physiol. 83, 236.

Flux, D. S. (1954). F. Endocrin. rr, 238.

Gerber, A., Raab, A. P. \& Sobel, A. E. (1954). Amer. F. Med. 16, 729.

Goodwin, T. W. \& Wilson, A. A. (1949). Biochem. F. 45, 370.

McGillivray, W. A. (1957). F. Dairy Res. 24, 102.

McGillivray, W. A., Thompson, S. Y. \& Worker, N. A. (1956). Brit. F. Nutr. ro, 126.

McGillivray, W. A., Thompson, S. Y. \& Worker, N. A. (1958). F. Dairy Res. 25, 439.

Moore, T. (r957). Vitamin A. Amsterdam: Elsevier Publishing Co.

Popper, H. \& Brenner, S. (1942). F. Nutr. 23, 43 r.

Thiele, W. \& Guzinski, P. (1940). Klin. Wschr. r9, 345.

Thompson, S. Y., Ganguly, J. \& Kon, S. K. (1949). Brit. F. Nutr. 3, 5o.

Wang, P., Glass, H. L., Goldenberg, L., Stearns, G., Kelly, H. G. \& Jackson, R. L. (I954). A.M.A. Amer. F. Dis. Child. 87, 659 .

Young, G. \& Wald, G. (1940-I). Amer. F. Physiol. 131, 2 ro. 